\title{
Non-Equilibrium Social Science and Policy
}

\author{
Jeffrey Johnson, Paul Ormerod, Bridget Rosewell, Andrzej Nowak, \\ and Yi-Cheng Zhang
}

\begin{abstract}
Between 2011 and 2014 the European Non-Equilibrium Social Science Project (NESS) investigated the place of equilibrium in the social sciences and policy. Orthodox economics is based on an equilibrium view of how the economy functions and does not offer a complete description of how the world operates. However, mainstream economics is not an empty box. Its fundamental insight, that people respond to incentives, may be the only universal law of behaviour in the social sciences. Only economics has used equilibrium as a primary driver of system behaviour, but economics has become much more empirical at the microlevel over the past two decades. This is due to two factors: advances in statistical theory enabling better estimates of policy consequences at the microlevel, and the rise of behavioural economics which looks at how people, firms and governments really do behave in practice. In this context, this chapter briefly reviews the contributions of this book across the social sciences and ends with a discussion of the research themes that act as a roadmap for further research. These include: realistic models of agent behaviour; multilevel systems; policy informatics; narratives and decision making under uncertainty; and validation of agent-based complex systems models.
\end{abstract}

\footnotetext{
J. Johnson (殴)

Faculty of Science, Technology, Engineering and Mathematics, The Open University, Milton Keynes, UK

e-mail: jeff.johnson@open.ac.uk

P. Ormerod • B. Rosewell

Volterra Partners, London, UK

e-mail: pormerod@volterra.co.uk; brosewell@ volterra.co.uk
}

\author{
A. Nowak \\ e-mail: andrzejn232@gmail.com \\ Y.-C. Zhang \\ University of Fribourg, Fribourg, Switzerland \\ e-mail: yi-cheng.zhang@unifr.ch
}

Faculty of Psychology, University of Warsaw, Warsaw, Poland 


\section{Introduction}

The European Non-Equilibrium Social Science (NESS) project that ran between 2011 and 2014 investigated the place of equilibrium in the social sciences and policy. NESS had its origins a year earlier in a late night discussion on economics and policy during a conference on complex systems in Shanghai. We were interested in the conundrum that, although orthodox economics had some questionable premises, it was widely used in policy. The purpose of the resulting project was not to reject existing economics, but to learn from and build upon it

We find that mainstream economics is not an empty box. Its fundamental insight, that people react to changes in incentives, is perhaps the only universal law of behaviour in the whole of the social sciences. It may often be difficult in advance to predict exactly what the effects of a change in incentives in any given situation might be. People can be very creative and innovative in how they adapt to change.

For example, do higher taxes on cigarettes improve human health? Higher taxes on products are usually passed on, in whole or in part, to the consumer in the form of higher prices. And higher prices reduce consumption, which in the case of cigarettes must lead to better health outcomes. The first part of the previous statement is very well established empirically in the economics literature. It is the second which is more problematic to establish, precisely because of the inventive ways in which smokers might react to higher prices.

A sophisticated statistical analysis by Adda and Cornaglia of US data across the states, published in the American Economic Review in 2013 [1], indicated two further ways in which smokers reacted to higher taxes, in addition to the obvious one of buying fewer cigarettes. First, there was a switch to higher tar brands. Second, making use of detailed data, the researchers showed an increased propensity amongst some groups to smoke further down towards the butt of the cigarette, where the concentration of potentially dangerous substances is higher. So, in essence, some smokers reacted to higher prices by increasing the intensity of their smoking, raising doubts about the positive impact on health which is the intended outcome of higher taxes.

This potential uncertainty of outcome, of predicting how people react to any particular change in incentives, can be readily observed across a wide range of areas. How much impact on crime do longer prison sentences have, and how cost effective are these compared to, say, trying to increase the probability of catching the criminal in the first place by having more police? Governments around the world want to reduce carbon emissions, but how far can higher taxes on energy consumption help them to achieve their aims? The so-called Tobin tax, named after the economic Nobel Laureate James Tobin, on transactions on foreign exchange markets, is often advocated as a way of reducing the number of speculative transactions and thereby dampening volatility. Yet some studies indicate that such a tax might have exactly the opposite outcome and actually lead to markets becoming more volatile.

These examples, and there could be many more, serve to illustrate the point that the human world is complex and difficult to manage. But in all these examples, 
incentives are at work. When policies change, people react and some, or even all, change their behaviour. This is what economic theory says should happen. And it is what does happen. Policy makers find economics useful for many reasons, but this is perhaps the key one. Economics in this respect gives an understanding of a situation which is based upon scientific principles. It gives the policy makers levers which they can operate. And it describes the outcome of such actions.

In the public perception, there appears to be a great deal of disagreement within economics. Issues such as GDP growth, unemployment, inflation-what economics describes as the 'macro' economy — are frequently discussed in the media. At this level, it is indeed often the case that there are substantial differences of view. During the financial crisis of the late 2000s, for example, some economists were in favour of bank bailouts, others were opposed. Both groups included Nobel Laureates. The disagreements are often not simply about empirics, but about the relevant theoretical framework to use. But at the so-called 'micro' level, where the focus is on how individuals make choices amongst alternatives, such as deciding whether to go to a restaurant or to the cinema, there is effective unanimity amongst mainstream economists on the relevant theoretical approach to use when analysing a problem. This is the 'rational' model of choice, which is examined in some detail in Chapter "Economics" of this book by Ormerod, and there is little point in anticipating the details of that discussion here. The relevant point for the moment is that it is on this model that economists base the proposition that agents react to incentives.

The differences between economists at this level are essentially about the empirics, about the magnitude of any change of behaviour which has either already taken place as a result of changes to the set of incentives, or which might take place in the future in response to a change which is envisioned now by policy makers. Economics has become much more empirical at the microlevel over the course of the past two decades. In his chapter Ormerod argues that this is due to two factors [11]. First, substantial advances in statistical theory, which enables better estimates of the effects of policy changes at the microlevel. The paper by Adda and Cornaglia mentioned previously illustrates some of the abstruse but important issues involved. The Nobel Laureates James Heckman and Daniel MacFadden have been prominent in these developments. Second, the rise of behavioural economics. Behavioural economics looks for empirical evidence about how agents-people, firms, governments-really do behave in practice. Its focus is to try to identify ways in which their behaviour differs from the ways in which the rational agent model predicts. But as the leading behavioural economist Richard Thaler remarks in his latest book [18] 'Without the rational framework, there are no anomalies from which we can detect misbehavior' (p. 251). He goes on to say 'the real point of behavioral economics is to highlight behaviors that are in conflict with the standard rational model' (p.261). So, behavioural economics is strongly linked to the mainstream model of economic theory. It does not discard the precepts of economic rationality and offer instead a different general model of economic behaviour.

It is not the purpose of this book to set out a root and branch critique of mainstream economics. This is why in the opening section of this chapter we have 
focused on an important strength of economics, and described a key way in which the discipline has moved forward in recent decades. Equally, however, economics does not by any means offer a complete description of how the world operates. It is very much a partial one. The financial crisis of the late 2000s in particular exposed weaknesses. The views of Jean-Claude Trichet, Governor of the European Central Bank during the economic crisis, have been widely quoted. In November 2010, he gave his opinion that 'When the crisis came, the serious limitations of existing economic and financial models immediately became apparent. Macro models failed to predict the crisis and seemed incapable of explaining what was happening to the economy in a convincing manner. As a policy-maker during the crisis, I found the available models of limited help. In fact, I would go further: in the face of the crisis, we felt abandoned by conventional tools'.

A fundamental feature of orthodox economics is that it is based upon an equilibrium view of how the economy functions. Economists have devoted a great deal of ingenuity in trying to explain how asset price bubbles emerge, and how massive shocks to the economy such as a global financial crisis can happen. But these efforts are set within the framework of equilibrium, in which the natural tendency of the economy is to move to a situation in which all markets clear and in which all factors of production, such as the labour force, are fully employed.

The approach of the NESS Project was built on existing economics in order to make it more realistic. This book examines how economics, in the wider context of the social sciences and policy, can benefit from incorporating the concept of nonequilibrium systems.

Section 2 of this chapter describes the contributions in the book, from the perspective of a range of social sciences. In contrast to economics, a common feature of the other social sciences is that they neither have equilibrium as a premise nor as a conclusion. For them empirical validation of theory remains fundamental, and equilibrium is not the starting point.

Section 3 considers social science in policy. The political process is different to the scientific process. Scientific truth is neither necessary nor sufficient for policy, and bringing science into policymaking is an art. Decision makers want scientists to provide single definitive answers to policy questions, even when science shows there are many possible outcomes of a policy action. In order to be relevant in policy the social sciences have to take context into account in their methods and theories. Government is itself a complex system, and the process of collective decision making is imperfectly understood. Combining science with policy making is difficult to achieve. Global Systems Science attempts to do this by providing new ways of coordinating complex systems science, informatics and citizen engagement in the service of policy making.

Section 4 concludes the chapter and brings together the findings of the NESS project as a roadmap for further research. 


\section{The Non-Equilibrium Social Sciences}

Since equilibrium plays such a large role in orthodox economics it is instructive to survey the approaches of some other social sciences to see how they model society and social change. As will be seen, none of them shares the empirical premises of orthodox economics and none of them require the concept of equilibrium .

Each of the social sciences has a focus which makes it distinct. For example, psychology is concerned with the individual within social groups, while sociology is concerned with the behaviour of social groups composed of individuals. Geography is focussed on both, since all human activity is spatially referenced. Geographers have always been concerned with population and the evolution of human settlements in the context of the physical environment, climate and connectivity. Political science focuses on steering and managing these social systems, and the power relationships that make this possible.

These traditional social sciences are all ways at looking at the same whole. In all of them, one finds micro- and macro-levels, and meso levels in between. Their dynamics all have short and long timescales, and all cases share the perplexing ambiguity between the individual as a person and the psychology of the individual when they are playing a role in a larger social structure. As this section shows, the individual social sciences fit within the emerging science of complex systems.

\subsection{Social Psychology and the Narrative Economy}

There are many theories of the human mind and how and why humans act as they do. There is no theory that can consistently predict how individual humans will behave, and if there were reflexivity would allow some individuals to behave differently in order to confound or benefit from the prediction.

Social constructionism is a theory of how individuals create, change and maintain their understanding of the world. Although the world exists outside human minds, individual and collective knowledge of the world is always a human and social construction. The evidence to support this is that, in any situation, two or more people will see it differently, sometimes very differently.

This book is concerned with how social science can support policy. The chapter by Nowak et al. [10] suggests that an important part of this is the construction of narratives, stories that have a beginning, a body, and an end. Meanings arise from coordinated human action and by people interpreting their world by building models of it and how it functions. In this context, narratives provide a natural way of acquiring meanings and conveying them to others. Narratives exist at all levels of social reality. They provide the structure by which an individual can understand the world, and know how to behave. Interacting individuals construct narratives as a bottom-up social process, with group narratives being a synthesis of stories describing individual experiences. Shared narratives allow people to find 
commonality in their experiences, providing coherence and enabling coordinated action.

At the macrolevel narratives define the system and its common culture. Sometimes narration may have more impact on an economy than hard data. Even the choice of which facts we refer to and those we do not may determine the leading narrative and hence the behaviour of people. Socio-economic processes can and should be analysed in line with narratives linking individuals, organisations and societies to better understand what is happening in the whole economic system.

\subsection{Sociology and Non-Equilibrium Social Science}

Equilibrium is not a key concept in sociology. In this book Anzola et al. [3] argue that sociology is multi-paradigmatic with significant disagreement regarding its goals and status as a scientific discipline. Despite this, sociology aims at identifying the main factors that explain the temporal stability of norms, institutions and individual practices; and the dynamics of institutional change and the conflicts brought about by power relations, economic and cultural inequality and class struggle.

Today, sociology embraces complexity principles through its growing attention to complex adaptive systems and non-equilibrium sciences, with human societies seen as highly complex, path-dependent, far-from equilibrium, and self-organising systems.

Agent-Based Modelling provides a new and coherent inclusion of complexity principles into sociology. Agent-based sociology uses data and statistics to examine the generative sufficiency of given microlevel hypotheses by testing the agreement between 'real-world' and computer generated macrostructures. When the model cannot generate the observed macrolevel behaviour, its underlying assumptions do not provide a strong candidate explanation. The separation between the explanatory and pragmatic aspects of social science has led sociologists to be highly critical about the implementation of social science in policy. However, agent-based modelling allows systematic exploration of the consequences of policy assumptions and makes it possible to model much more complex phenomena than previously. It has proved particularly useful in representing policy-relevant socio-technical and socioecological systems, and offers formalised knowledge that can appear familiar to policymakers. Computational sociology through agent-based modelling is likely to become increasingly more influential in policy.

\subsection{Geography Far from Equilibrium}

Pumain's chapter in this book [12] explains that geography makes little use of the concept of equilibrium. Geographical inquiry is based on the recognition of 
differences and asymmetries among regions and civilisations, and the search for explanations to the great variety of landscapes and ways of life.

Modern geographers study both the 'vertical' interactions between societies and their local milieu and the 'horizontal' interactions between cities and regions. This involves two opposing causes of territorial inequalities, spatial diffusion of innovation and urban transition.

Whereas diffusion of innovation alone might result in homogeneity, combined with the dynamics of city formation the result is increasing heterogeneity and inequality. The phenomenon of increasing returns with city size is explained by higher population densities and connections multiplying the probability of productive interactions, as well as by adaptive valuation of accumulated assets.

While there may be great wealth, in some urban agglomerations large informal settlements of slums and shanties are still expanding. Global societal evolution is an open process with no fixed asymptotic point in the future: there is no final equilibrium state for the world to reach. Open evolution may hamper the quality of predictions that can be made about the future, but geographical knowledge of past dynamics may help to make forecasts more certain. Powerful analytical tools have been developed in the last five or six decades that greatly improve the quality of geographical work and its ability to provide stakeholders and decision makers with clearer insights for exploring possible territorial futures.

Detailed geographical information from many data sources enables a shift from a macro-static view to a micro-macro dynamical view that is necessary for management and planning policies in a non-linear world. In this, geography is at the forefront of computational modelling for policy, and as a science geography remains deliberately far from equilibrium.

\subsection{Cities in Disequilibrium}

Batty's chapter [4] shows that, although cities may seem to be largely stable in spatial structure over long periods of time, this is a superficial perception. To a large extent, this view of cities in equilibrium is borne of thinking about them physically. Cities are always in disequilibrium. They are in fact far-from-equilibrium, being maintained through a tension between many countervailing forces that break down and build up on many different spatial and temporal scales, thus all coalescing in strong volatility and heterogeneity in urban form and function.

We should think of cities as being far-from-equilibrium structures and allude to ideas about innovation and technological change that condition their dynamic entirely. What happens in cities is increasingly disconnected from their physical form. This is particularly the case in the contemporary world where changes to the built environment are ever out-of-sync with changes in human behaviours, activity locations, patterns of movement, and globalisation. 


\subsection{International Relations}

Root's chapter in this book [14] illustrates the powerful hold of equilibrium thinking on international policy. Convergence theory, developed in the West for half a century, is based on the hypothesis that there are irresistible forces driving the world to converge towards an inevitable equilibrium state - and the world will eventually be made up of liberal capitalist democracies like those in Western countries.

Steps towards this include the failure of Soviet communism as an efficient system for the production and distribution of goods and services, the structural crisis of Swedish socialism, the reversal of French socialism, and the increasing if limited economic liberalisation of China

Modernisation theory sees the way to achieve this as being through the adoption of free market capitalism tied to optimal forms of democratic governance. In this way all countries in the world will converge to an optimum equilibrium state.

As Root shows, although the evidence is against the inevitability of convergence, this theory is the basis of conflicts in the Middle East initiated by Western powers that did not achieve their policy objectives. The failure of international policy can either be viewed as a setback on the way to the optimum global liberal capitalist free market democracy, or as a series of steps into the unknown. Root makes a comprehensive argument against convergence theory and concludes that divergence is a response to heightened interconnectivity. Thus the science of complex systems offers a way to provide insight into the mechanisms of international development, and overcome the limitations of conventional analysis in political economy.

\subsection{Systems, Networks and Policy}

Johnson, Fortune and Bromley's chapter [9] introduces the formal concept of a system as a set of interacting parts. Systems thinking has a long history and a variety of methods to capture the dynamics of systems to better understand them. Feedback is a fundamental property of systems and can make them highly unpredictable. Complex systems have multilevel network dynamics with bottom-up and top-down feedback and understanding these better is essential for policy. Often computer simulation is the only method to investigate the future behaviour of many systems, and since they are invariably sensitive to initial conditions, it is necessary to run many simulations to map out the space of future possibilities. In general it is impossible to give a prediction that a social system will be in a particular state at a particular time, but it is possible to investigate the range of possible futures through systems modelling and network science. 


\subsection{Complexity Friendly Economics}

Squazzoni's chapter in this book discusses the limitations of orthodox equilibrium thinking in policy and explores more complexity-friendly alternatives [17].

If societies and markets are viewed as complex non-equilibrium systems, for policy purposes it will be necessary to understand the nonlinear, adaptive and evolving patterns that emerge from agent behaviour in networks. This requires improved realism of the behavioural and social foundations on which policies are based. Also it is necessary to reconsider incentivisation, institutional design and the top-down regulation that typically dominates conventional policy. Recent cases of financial market regulation and health policies illustrate the subtle ways in which people or organisations behave when exposed to social influence, and pre-existing social norms and network externalities.

\subsection{The Information Economy}

The chapter by Zhang outlines a novel theory of the consumer market, in which information plays the key role [19]. It is assumed that consumers know only part of the available business offers and cannot ascertain the quality of the products they desire. Businesses have even less knowledge of what consumers desire. Thus, in the market consumers and businesses must find a match with severely deficient information. Instead of optimisation under constraints, the theory focuses on how the information constraints can be gradually reduced. Constraint-reduction does not lead to the full information limit typically portrayed in mainstream economics. Instead both consumer wants and business offers expand with concomitant new information deficiencies. Therefore the consumer market is always in nonequilibrium and information will always be deficient. As a consequence, wealth is created in the dynamic pursuit to reduce information constraints, and this is the main driving force that powers economic growth.

\subsection{Towards a New Economics}

Ormerod's chapter [11] addresses the question of whether the commanding position of orthodox economics in the policy making process is justified by its scientific achievements. Despite the failure of its macro-level Dynamic Stochastic General Equilibrium models to provide useful guidance following the financial crash of 2008, at the microlevel economics provides the general law that individuals react to changes in incentives. The foundational behavioural assumptions of orthodox economics are increasingly called into question in the twenty-first century, especially in the context of decisions taken in cyber space. For example, alternatives are being 
proposed to rational choice theory, which assumes agents have stable preferences, their preferences are independent of others, and they can gather and process large amounts of information.

Herbert Simon challenged the orthodox approach. He proposed that agents make choices by bounded rationality which depends on the particular problem, the information available, agents' cognitive limitations, and the time available to make a decision. This involves the use of heuristics to find candidate solutions, and satisficing. The concept of satisficing in the sense of Simon is fundamentally different to what it has come to mean within mainstream economics. In the latter, agents carry out limited search activity and find a satisfactory rather than the optimal solution, judging that the costs of gathering more information outweigh the potential benefits. In contrast, Simon argued that agents do not attempt to optimise in many contexts. 'Satisficing' means adopting a heuristic decision rule which gives satisfactory results. Although Nobel laureates Akerlof, Stiglitz, Kahneman and Smith developed Simon's programme in the 1960s and 1970s, economists have sidestepped the implications of bounded rationality in the sense of Simon by asserting satisficed solutions can be improved incrementally, rather than there being no optimum.

Economics does not stand still. For example, it has embraced the concept of asymmetric information, where buyers and sellers may have different knowledge of what is on offer. The notion of market failure followed this, the idea being that if the world did not correspond to the model, then policy intervention was need to correct this failure in the market. One common policy response today is regulation to provide consumers with more information to reduce the asymmetry, for example in the oligopolistic retail markets of power and telephony.

Ormerod concludes that key areas of research include: agent decision making rules; heuristics to identify decision types in any given context; network percolation of imitation, incentives, ideas, beliefs, influence and sentiments; networks evolution; the policy implications of different modes of behaviour; fundamental theory and tools to operationalise narrative dynamics; computational theories of narratives, including Big Data; tools for processing narratives and sentiment; and predicting the emergence of narratives.

\section{Social Science in Policy}

\subsection{Complexity Science and the Art of Policy Making}

Rosewell's chapter [15] views policy making as a combination of science and art, with complexity science bridging evidence-based science and the art of balancing hypotheses which are not or cannot be tested. First she contrasts the nature of proof in science and decisionmaking and shows that, although there is scientific modelling in the economic analysis of public policy, the decisionmakers can privilege tradition 
over evidence and proof e.g. by favouring one form of model over another, or arguing that 'we have been doing it this way for years so it must be right'. Second she looks at optimisation, in the context of a widespread belief that the benefits of policy investments can be optimised. A complex systems approach suggests that individuals do not optimise but use strategies such as copying to get good if not perfect outcomes, while firms may not optimise, for example due to risk aversion or lack of information. Thirdly, she considers the 'do nothing' policy option. An equilibrium approach suggests that doing nothing will leave things unchanged, but as a complex systems perspective suggests, the world will change even when the policy maker does nothing, possibly for the worse. It is concluded that risk free investments and policies are not possible, and the important thing is to have a strong story backed by strong evidence. Creating that story is a combination of art and science.

\subsection{The Complexity of Government}

Fisher's chapter [8] argues that we have an imperfect understanding of collective action and, until we do, considerations of the role and scope of government will be based on crude impressions or ideologies. The economic success of capitalist countries can in part be attributed to people being free to form organisations. Such collective action includes social governance, defined here as all forms of institutions whose role is to facilitate, or enable, collective action. There are different levels of collective action in governance, with national governments at the highest level cascading permissions and power to other organisation forms in public and private sectors. Government and libertarianism have a natural tension in the balance of power at all levels. In democracies it is necessary to have effective means of preventing those with partial power using it to gain total power. This includes non-elected organisation, e.g. today some multinational companies have greater wealth than some countries and use their financial power to support regimes sympathetic to their corporate interests. The dispassionate science of complex systems could provide a fresh perspective on what has been an historically emotive and inconclusive debate.

\subsection{Context-Dependency in the Social Sciences}

Edmond's chapter [7] discusses how context is crucial for understanding social phenomena, but sometimes context is absent leading to spurious averaging generalisation, while sometimes contextual detail is everything but there is no generalisation.

Three ways forward are proposed. (1) Using data mining techniques to look for patterns whose output fits behaviours across a range of target behaviours, and combining these overlapping models to create a context. (2) Context-dependent 
simulation modelling, with the memory of the agent being context-sensitive, and context-relevant knowledge and behaviours being applied in decision-making. This architecture has advantages in terms of agents learning or reasoning, but may require more knowledge in order to specify the agent behaviours for all the relevant contexts. However, it is argued that this is necessary for the adequate representation of behaviour. (3) Combining qualitative and formal approaches. For example, agentbased modelling can use qualitative evidence to inform the behavioural strategies that people use in given situations, with simulations based on microlevel behaviours producing numbers for comparison with macrolevel quantitative data. This supports experimentation to understand emerging processes, and investigate the qualitative assumptions and the quantitative evidence.

Explicitly recognising and including context-dependency in formal simulation models allows for a well-founded method for integrating qualitative, quantitative and formal modelling approaches in the social sciences. Formal simulation models can include qualitative ethnographic, observational and interview data, and can enrich quantitative analysis, leading to better models and understanding of human behaviour and more effective ways of collecting, integrating and analysing data.

\subsection{Global Systems Science and Policy}

The chapter by Dum and Johnson discusses how complex systems science can be integrated with policy [6]. 'The vision of Global Systems Science (GSS) is to provide scientific evidence to support policy-making, public action and to enable civil society to collectively engage in societal action. Policy makers suffer from an intrinsic difficulty when addressing challenges such as climate change, financial crises, governance of pandemics, or energy sufficiency since the impact and unintended consequences of public policy action are increasingly hard to anticipate. Such challenges are global and connect policies across different sectors'. ${ }^{1}$

There are many reasons why social systems cannot be predicted in a conventional sense. The science of complex systems provides new computer-enabled approaches to exploring the consequences of policy. Global System Science combines policydriven questions with the interdisciplinary science of complex systems, policy informatics as the integration of that science into useful policy computer tools, and the engagement of citizens to drive and legitimate policy.

GSS clarifies the relationships between scientists, policy makers and citizens. The normative aspect of policy-how the world ought to be-is the legitimate concern of citizens and policy makers. Whereas science is essential for evidencebase policy, it must be accessible to policymakers and citizens. Policy informatics provides a practical means for this by requiring science to be presented in comprehensible ways through computer-based tools and interfaces. In this way scientists

\footnotetext{
${ }^{1}$ https://ec.europa.eu/digital-single-market/en/global-systems-science.
} 
can help citizens and policy makers to generate and investigate the consequences of policy options. As this book makes clear, there is rarely an optimum solution and policy problems have to be satisficed. As Rosewell's chapter suggests [15], choosing between options is an art rather than a science. The job of scientists is to make the options and their likelihood as clear as possible, but not to make the decisions.

\section{Conclusion: A Roadmap for Further Research}

In this section we summarise the key themes that emerged from the NESS project, and signpost community-driven directions for future research. A central challenge is to develop areas of work which have the potential to unify much of the analysis carried out in the different social sciences.

We agree with a basic premise of mainstream economics that explanations of phenomena which emerge at the meso or macrolevels must be grounded in the microlevel foundations of the rules of agent behaviour. However, the underlying assumptions of economics are much less relevant in the twenty-first century, and existing social science is either unable to explain events to policy makers, as during the financial crisis, or its theory gives misleading advice. There is no point in pursuing research which is solely based upon agents behaving as optimisers subject to constraints-a paradigm which has now been tested to destruction. Based on the experience of the NESS project we propose research to develop the new paradigms of complex systems science and computational social science for policy.

\subsection{Research Theme 1: Realistic Models of Agent Behaviour in the Twenty-first Century}

There is now a vast proliferation of alternatives from which consumers can choose, e.g. in New York City there are 10 billion (!) different products and services available [5]. The huge explosion in ICT means that consumers are much more aware of the decisions, actions and opinions of others. Our world is radically different from that in which modern economic theory was first formalised in the late nineteenth and early twentieth centuries. Two classic articles in economics by Alchian in 1950 [2] and Simon in 1955 [16], argued that, under most circumstances, agents cannot optimise. Even ex post, often it is not possible to identify what the optimal decision would have been. Both Alchian and Simon came to the conclusion that, in a rapidly changing environment, agents use instead simple rules of thumb to make decisions. In particular, imitation of some kind will often be a good decision rule. This conclusion is supported, decades later, by the social learning tournament reported in Science [13]. 
Key streams of research to support are:

- Identification of the decision making rules followed by agents in the twenty-first century, in particular how and when agents imitate the decisions of others, and when they do not

- Developing heuristics which enable us to identify which of these rules predominate in any given context

- Expand our knowledge of networks, especially how choices between alternatives spread, including products, innovations, ideas, and beliefs. Much is now known about this when the behaviour of nodes and the topology of the network are fixed, but this needs to be extended to evolving behaviours and topologies

- To articulate the policy implications of these different modes of behaviour. In particular, if imitation is a stronger motive than incentives, the policy implications for policy are profound

\subsection{Research Theme 2: Multi-level Systems}

Although mainstream economics correctly insists on micro foundations of meso and macrolevel phenomena, in general it lacks feedback across these different levels, and lacks a scientific formalism for this. A distinguishing feature of Global Systems and Complex Systems Science is that there are multiple feedbacks in a system, a concept present in policy debates for many years, e.g. in the 1970s work on Limits to Growth.

Key streams of research to support here are:

- New mathematical methods for representing multilevel systems and inter- and intra-level dynamics.

- How to model 'necessary' and 'sufficient' combinations to generate particular outcomes

- How data can be selected and collated to capture both levels and change through time

- Large scale demonstrators involving stakeholders, including policy makers

\subsection{Research Theme 3: Policy Informatics}

Complex Systems Science has been mostly been funded by the European Commission through FET (Future and Emerging Technologies) which had a focus on ICT in FP7. In Horizon 2020 the mission of FET has been extended but still includes a strong emphasis on ICT.

The concept of policy informatics is central to Global Systems Science and policy-oriented applications of complex systems science. Much of our research requires very large-scale computation using very large data sets across very large 
communications systems (although it is important to explore parallel policy analysis based on small-scale complexity models). With notable exceptions, our research community has not connected well with policy makers.

Key streams of research and coordination to support here are:

- Use of computers to support policy at all levels of government

- The interface between scientists, technologists, business people, citizens and policy makers

- Visualisation (visual analytics) to present technical outputs in intuitively understandable ways.

\subsection{Research Theme 4: Narratives and Decision Making Under Uncertainty}

In many situations, decision makers are faced with genuine uncertainty. Little or no information is available on the probability distribution of outcomes. This is particularly the case with decisions that are difficult to reverse, and which have consequences which extend beyond the immediate future.

In finance, standard and behavioural theories are a hindrance-perhaps a defence against the anxieties created by uncertainty and lack of control. They miss the point that although financial assets must ultimately depend on some kind of 'fundamental', human beings have to use their interpretive skills to infer what these values are. They have no given value in and of themselves. The value depends on buyers' and sellers' reflexive views as to the future income streams generated by the fundamentals of the underlying entities.

Under uncertainty, decision makers require narratives which give them the conviction to act, rather than being paralysed into inactivity. Narratives-how the facts are perceived - are crucial in many contexts. For example, in the current debate over austerity, the impact of a change in fiscal policy would depend upon how this was perceived by the markets, and how this perception translated into interest rates on government bonds.

Key streams of research to support here are:

- Fundamental theory and tools which operationalise the concept of narratives

- Computational theories of narratives, including Big Data

- Tools which develop our understanding of how narratives either spread or are contained

- Tools to enable early prediction of narratives which have the potential to develop traction 


\subsection{Research Theme 5: Validation of Agent-Based Complex System Models}

For policy makers, a key attraction of recommendations based on economics is that economists claim that their models are scientifically validated. There is a shared belief across economists as to what constitutes a valid model. This is missing for complex systems approaches such as agent-based modelling, and is essential for complex systems science.

The key stream of research to support here is:

- To fund the development of agreed criteria in this community for what constitutes a valid scientific model. This is essential in order to instil confidence amongst policy makers in the recommendations arising from these models.

\subsection{Research Theme 6: Global Systems Science}

Global Systems Science adds to the themes above by clarifying the relationship between scientists, policy makers and citizens. The research themes above are necessary for complex systems science to give better understanding how social systems work, and GSS can be instrumental in making its new scientific knowledge accessible to citizen-engaged policy.

Key streams of coordination and research to support here are:

- Coordinating complex systems scientists, policy makers, citizens

- Creating exemplar GSS projects involving scientists, citizens, other stakeholders and policy makers addressing real world problems

Acknowledgements This work was supported by the Non-Equilbrium Social Science (NESS), Global Sysems Dynamics and Policy (GSDP), and Topology-Driven Methods in Complex Systems (TOPDRIM) Projects of the Future and Emerging Technologies (FET) division of the European Commission 2010-2016.

Open Access This chapter is distributed under the terms of the Creative Commons Attribution 4.0 International License (http://creativecommons.org/licenses/by/4.0/), which permits use, duplication, adaptation, distribution and reproduction in any medium or format, as long as you give appropriate credit to the original author(s) and the source, provide a link to the Creative Commons license and indicate if changes were made.

The images or other third party material in this chapter are included in the work's Creative Commons license, unless indicated otherwise in the credit line; if such material is not included in the work's Creative Commons license and the respective action is not permitted by statutory regulation, users will need to obtain permission from the license holder to duplicate, adapt or reproduce the material. 


\section{References}

1. Adda, J., Cornaglia, F.: Taxes, cigarette consumption, and smoking intensity. Am. Econ. Rev. 96(4), 1013-1028 (2006)

2. Alchian, A.A.: Uncertainty, evolution, and economic theory. J. Polit. Econ. 58(3), 211-221 (1950). http://www.kysq.org/docs/Alchien.pdf

3. Anzola, D., Barbrook-Johnson, P., Salgado, M., Gilbert, N.: Sociology and non-equilibrium social science. In: Johnson, J.H., Nowak, A., Ormerod, P., Rosewell, B., Zhang, Y.-C. (eds.) Non-Equilibrium Social Science and Policy. Springer, New York (2016)

4. Batty, M.: Cities in disequilibrium. In: Johnson, J.H., Nowak, A., Ormerod, P., Rosewell, B., Zhang, Y.-C. (eds.) Non-Equilibrium Social Science and Policy. Springer, New York (2016)

5. Beinhocker, E.: The Origin of Wealth: Evolution, Complexity, and the Radical Remaking of Economics. Harvard Business School Press, Boston (2006)

6. Dum, R., Johnson, J.: Global systems science and policy. In: Johnson, J.H., Nowak, A., Ormerod, P., Rosewell, B., Zhang, Y.-C. (eds.) Non-Equilibrium Social Science and Policy. Springer, New York (2016)

7. Edmonds, B.: The room around the elephant - tackling context-dependency in the social sciences. In: Johnson, J.H., Nowak, A., Ormerod, P., Rosewell, B., Zhang, Y.-C. (eds.) NonEquilibrium Social Science and Policy. Springer, New York (2016)

8. Fisher, G.: The complexity of government. In: Johnson, J.H., Nowak, A., Ormerod, P., Rosewell, B., Zhang, Y.-C. (eds.) Non-Equilibrium Social Science and Policy. Springer, New York (2016)

9. Johnson, J., Fortune, J., Bromley, J.: Systems, networks and policy. In: Johnson, J. H., Nowak, A., Ormerod, P., Rosewell, B., Zhang, Y.-C. (eds.) Non-Equilibrium Social Science and Policy. Springer, New York (2016)

10. Nowak, A., Kacprzyk-Murawska, M., Serwotka, E.: Social psychology and the narrative economy. In: Johnson, J.H., Nowak, A., Ormerod, P., Rosewell, B., Zhang, Y.-C. (eds.) NonEquilibrium Social Science and Policy. Springer, New York (2016)

11. Ormerod, P.: Economics. In: Johnson, J.H., Nowak, A., Ormerod, P., Rosewell, B., Zhang, Y.-C. (eds.) Non-Equilibrium Social Science and Policy. Springer, New York (2016)

12. Pumain, D.: Geography far from equilibrium. In: Johnson, J.H., Nowak, A., Ormerod, P., Rosewell, B., Zhang, Y.-C. (eds.) Non-Equilibrium Social Science and Policy. Springer, New York (2016)

13. Rendell, L., Boyd, R., Cownden, D., Enquist, M., Eriksson, K., Feldman, M.W., Fogarty, L., Ghirlanda, S., Lillicrap, T., Laland, K.N.: Why copy others? Insights from the social learning strategies tournament. Science 328, 208-213 (2010). doi:10.1126/science.1184719

14. Root, H.: Global political dynamics and the science of complex systems. In: Johnson, J.H., Nowak, A., Ormerod, P., Rosewell, B., Zhang, Y.-C. (eds.) Non-Equilibrium Social Science and Policy. Springer, New York (2016)

15. Rosewell, B.: Complexity and the art of policy making. In: Johnson, J.H., Nowak, A., Ormerod, P., Rosewell, B., Zhang, Y.-C. (eds.) Non-Equilibrium Social Science and Policy. Springer, New York (2016)

16. Simon, H.A.: A behavioral model of rational choice. Q. J. Econ. 69(1), 99-118 (1955)

17. Squazzoni, F.: Towards a Complexity-Friendly Policy: breaking the vicious circle of equilibrium thinking in economics and public policy. In: Johnson, J.H., Nowak, A., Ormerod, P., Rosewell, B., Zhang, Y.-C. (eds.) Non-Equilibrium Social Science and Policy. Springer, New York (2016)

18. Thaler, R.H.: Misbehaving: The Making of Behavioural Economics. W. W. Norton \& Co, New York (2015)

19. Zhang, Y.-C.: The information economy. In: Johnson, J.H., Nowak, A., Ormerod, P., Rosewell, B., Zhang, Y.-C. (eds.) Non-Equilibrium Social Science and Policy. Springer, New York (2016) 